\title{
Enthusiasm, trust and its erosion in mediated politics: On fans of Obama and the Liberal Democrats
}

\section{Cornel Sandvoss}

University of Surrey, UK

European Journal of Communication

27(1) 68-81

Reprints and permission: sagepub. co.uk/journalsPermissions.nav

DOI: $10.1177 / 0267323111435296$

ejc.sagepub.com

\section{Corresponding author:}

Cornel Sandvoss, Department of Sociology, University of Surrey, Surrey GU2 7XH, UK.

Email: c.sandvoss@surrey.ac.uk 


\section{Abstract}

This article explores the interplay of political enthusiasm as a form of fandom and the creation and disappearance of trust as a result of the evolving relationship between fans and their objects of fandom. Drawing on semistructured interviews with supporters of Barack Obama and the UK Liberal Democrats, the article illustrates how the bond between fans and their political fan object is built in the highly polysemic environment of convergence media in which audiences actively construct textual boundaries. Based on projective and self-reflective readings, enthusiasts of given political causes, actors or parties thus build an affective attachment to their fan object which allows for the creation of trust in its perceived proximity. If such readings become unsustainable over time, this affective bond and its associated levels of trust are eroded.

\section{Keywords}

fans, Liberal Democrats, Obama, political communication, political enthusiasm, trust 
Invesco Field, home of two-times Super Bowl Champions Denver Broncos, is no stranger to hoards of cheering fans. However, the tens of thousands of enthusiastic supporters that had gathered here in August 2008 did not converge on the arena to watch their favourite sports team or favourite band, but to cheer on Barack Obama as newly nominated Democratic Party presidential candidate.

This article explores two noteworthy, yet often overlooked, aspects of the celebration of Obama's nomination and similar instances of enthusiastic political support: first, the grassroots support that drove Obama's campaign to victory was foremost an expression of trust. In a campaign that centred on the motif of change and hope, 1 enthusiasm was rooted in expectations of future political action. Giddens (1990), in his much cited analysis of modern societies, identifies trust as the premise for the operation of disembedding mechanisms indispensible to the operation of modern societies. Whereas Giddens focuses on trust in monetary exchange and expert systems, Obama's supporters illustrate that representative democracies, as a further disembedding mechanism of the nation-state, are equally dependent on trust.

Second, the setting of a multipurpose entertainment venue highlights the similarities between the enthusiasm of Obama's supporters and the affective involvements in realms of popular culture we commonly describe as 'fandom'. Over the past decade a growing body of work has examined the interplay between forms of popular and political communication, exploring the way in which the consumption of different areas of popular culture has created spaces for political discourse and debate (Van Zoonen, 2005) from broader political and attitudinal questions concerning gender or race to the more narrowly political.2

Beyond the documentation of the political significance of forms of popular media consumption, a second body of work has emerged which examines the similarities and differences between political engagement and activism and the enthusiasm of audiences of popular TV formats. Coleman (2003), for instance, compares those with a high interest in political coverage with viewers of the popular reality TV format Big Brother and acknowledges the gulf between both groups in their view of what constitutes relevant and worthy engagement. Coleman (2003: 756) warns: 'democracy is ultimately unsustainable, if the demos is estranged from it'. This article suggests a third variation on the interpretation of the crossover between popular and political communication - though one that like Coleman will return to concerns over the sustainability of contemporary systems of electoral representation and political communication: it suggests that forms of political engagement in mediated, indirect democracies are based on affective reading formations of (largely mediated) texts that are not like forms of fandom, but that are a form of fandom and that hence can be meaningfully analysed by drawing on the burgeoning field of fan studies. The trust that supporters placed in the presidential candidate Barack Obama in 2008 was based on an affective attachment that this article argues is a form of fandom that helps us to analyse the creation and erosion of trust in mediated democracies.

\section{Methodology}

This article is based on the study of supporters of two recent political movements, which both shared an emphasis on the theme of 'change' by breaking the dominant patterns: the election of Barack Obama as Northern, anti-war and, most notably, black Democrat in 2008 and the rise and fall of the British Liberal Democrats (LibDems), who in the polling prior to the 2010 UK general election came within single digits of the postwar ruling parties, Labour and Conservative, and subsequently entered government for the first time as partners in a coalition with the Conservatives. In analysing their supporters' affective attachments, this article draws on the tradition of qualitative audience research, the dominant method of empirical contributions to fan studies. Using key techniques of ethnographic research, such as participant observation, informal interviews and semi-structured interviews, this research, as other fan studies, is confronted with the difficulty of a nonterritorial field and community under investigation. In contrast to the traditional ethnographer, the fields of study thus remain either dispersed (the lifeworld of individual media consumers) or largely virtual (spaces of communication and discourse). I therefore draw on the close observations of these two political movements through informal and unstructured interviews, the monitoring of related online exchanges in message groups, online fora and social media, as well as semi-structured interviews, conducted face-to-face as well as via email, between 2008 and 2011. The data generated by this research exploring the wider question of enthusiasm and political fandom and their interplay with the textuality of political communication are used selectively to focus on aspects highlighting the interplay of affective attachments, textual neutrosemy (the absence of textual meaning; see Sandvoss, 2005b) and trust.

\section{Supporters or fans?}

The claim that these supporters can be described as fans forms the premise of my argument here. With the growth of the field of fan studies since key foundational work by, among others, John Fiske and Henry Jenkins in the late 1980s and early 1990s, the question of the definition of the labels of 'fan' and 'fandom' has been 
widely discussed. In this article I am less concerned with the communal aspects of close-knit groups of media consumers but instead examine the affective attachment of fans to mediated objects which, whether individual politicians or political parties, are always encountered, read and negotiated as forms of texts; texts that are increasingly transmitted and narrated in and through different, yet also converging media platforms. 3 Fandom here, therefore, does not describe a particular fan culture, but the state of being a fan, which in turn I have defined as 'the regular, emotionally involved consumption of a given popular narrative or text' (Sandvoss, 2005a: 8). This broad definition does not rely on self-classification of audience groups as fans - which mirror dominant perceptions of the label - but instead focuses on practices and affective engagements. As a consequence we can critically examine forms of audienceship in realms outside traditional popular culture such as art (see Gray et al., 2007) or indeed politics.

Like television, music or sports fans, supporters of political figures or parties are committed and regular readers, viewers and listeners to a wide range of mediated text as part of election campaigns. The following two Obama supporters are illustrative of both the quantity and scope of many political enthusiasts' media use:

I follow the campaign daily. I read CNN.com, the New York Times, and the Huffington Post. I do not have a television, but I try to watch news broadcasts over the internet. Following the campaign takes up a lot of time, 3-4 hours per day ... I check my sources of information in the morning, at lunch, and in the evening after dinner, or while I am cooking dinner. (Joanne, 22, from Vermont)

I read the NY Times online daily (and get the paper edition on Sundays, which I don't always get to read in the same week), as well as Salon.com a few times a week. I also read Tuesdaysblog.com and its companion site Nomoremccain.com. I read Salon.com's online community, Table Talk (although I am not active there) - there are a number of election threads there that are a great source of information. I also follow links posted by my Facebook friends, most of whom are politically interested and/or active. I listen to NPR every morning and afternoon, and don't watch TV news really at all - but I do see it when I'm at the gym, with headphones in. I listen to the BBC as well, it plays on our local NPR station in the late-night hours. I can sometimes catch The Daily Show when I'm at the gym. (Lisa, 39, from Wisconsin)

The diverse media and genres these supporters utilize in following the campaign mirror the heavy media use of fans of popular culture. Like other fans, those with a particular interest in a given political cause make use of the spectrum of different media with the aim to negotiate and appropriate texts to match their distinct horizons of expectations (Jauss, 1982; see also Sandvoss, 2011b). However, fans do not only negotiate a given text, but in a convergent media environment are also required to determine the boundaries of a given text. As we move from media whose boundaries are constructed at the point of consumption and enforced through their physical form or the conventions of public consumption (such as the novel, a film watched at the cinema or a painting) to mobile and domestic media whose textuality is both more ephemeral and limitless, audiences are required to formulate textual boundaries at the point of consumption (Sandvoss, 2005b, 2007a).

The construction of textual boundaries and hence the appropriation of texts in their content and form adds another facet to the repertoire of the reader: out of the 'textual fields of gravity' rather than clearly defined texts that surround political parties and actors, their supporters include and exclude particular textual episodes in their reading and subsequent construction of meaning. During the US presidential campaign, for example, supporters carved the text that came to serve as their fan object (Obama) out of the multitude of conflicting discourses among the range of media outlets, social media and of course rival campaigns. Below, Obama fan Jessica explains why she avoids campaign literature by the Republicans and associated media outlets:

I can accept that it is expected for politicians to lie but I cannot accept the fear tactics and the smears they have exhibited. It is one thing to disagree and to critique and attack the opposing ticket, but it is another to make false lies, accusations, and claims about them and then to perpetuate it. (Jessica, 23)

Similarly, Andrea identifies a partisan habitus in the selection of information about the campaign that is also shared by her peers:

As to discussing whether or not to support Obama - I don't deal regularly with anyone who doesn't; 'democrats are

good', 'republicans are bad' is a pretty good summary of what most of my friends and family believe. (Andrea, 27)

Fans thus select between a vast number of paratexts rather than urtexts (Sandvoss, 2007a). Possibly more than any other audience group, supporters of political parties therefore not only construct the boundaries of their fan text, but they alongside fellow audience members take a particularly active role in contributing to the textual field from which the text is selected - contributing to a degree of polysemy that borders the absence of intersubjective meaning which I describe as 'neutrosemic'.

Naturally, how such boundaries are constructed and the degree to which fans engage in different forms of productivity in doing so varies among different groups. Elsewhere (Sandvoss, 2011a) I have suggested that the three types of fan productivity John Fiske (1992) identifies - semiotic, enunciative and textual - can be meaningfully correlated with those who have the broadest fan object and lowest degree of social connectivity through their fandom mainly being semiotically active, whereas enthusiasts who, closely connected with other activists, find the object of fandom increasingly in their own activity are also enunciative and textually active (cf. Abercrombie and Longhurst, 1998). For these fans, participating in discussions with fellow supporters allows them to play an active role in writing the fan text through their enunciative productivity while at the same time becoming more specialized in their own media use. Martin, a 30-year-old LibDem supporter from London, 
is typical of such specialized media use in opting out of the use of some mainstream media (such as television) while relying heavily on discussions with friends and peers:

I use the BBC for the core news, bit of Radio 4 . . I don't have a TV. Well, I do watch Question Time every week ... usually just a good way of seeing what everyone's arguments are about some key issues; mostly the BBC website and then reading; someone who used to work here had a subscription to a publication called The World Today, and that's a really good publication ... and yeah, then to be honest, talking to friends, I got a lot friends engaged . . . well not directly engaged in politics but politically minded. . . . Some of the friends I have made, I have made because of political leanings and ideas.

Communication and debates, especially online, appear to offer political supporters membership to the 'interpretive communities' (see Jenkins, 1992) of particular fan cultures. These were frequently identified as central in building and maintaining support for a given political candidate or party. Carla, a 52-year-old Obama fan, from Georgia, a socially conservative state that has been in the Republican column since Bill Clinton's narrow victory there in 1992, identified discussions with a friend as the catalyst for becoming interested in Obama campaign:

Having been a Republican my entire life, I didn't pay much attention and voted for Huckabee in the primaries. My 68year-old friend visited me the day of the primary vote and said he had voted for Obama - the first time he had ever voted Democratic because 'Obama is the only exciting candidate running'. This man's endorsement caught my attention because I respect his opinion.

Subsequently, discussions with fellow fans via online groups and social media become central to building her support of Obama:

My participation in the Facebook group 'Barack Obama (One Million Strong)' has provided an excellent venue to get the latest news, read opinions on all sides of every issue, and re-consider some of my own long-held beliefs. As a pro-life supporter, supporting Obama was difficult. The Facebook group discussions have helped me to understand the underlying issues that surround abortion, and I realized I could be both pro-life and pro-Obama.

Her participation in this interpretative community in turn served as the basis for Carla's activism throughout the campaign, reflected in high levels of enunciative and textual productivity:

My friends and family have said that I am 'outspoken and obsessed' and an 'activist for Obama'. In small town Georgia, being a middle-aged white female is not the usual profile of an Obama supporter. . . I I have spent many hours responding to smear emails from members of my church, as well as friends and family members. The unfairness and vicious 'gossip' campaign to defeat Obama has opened my eyes to the racial fear that exists in the southern United States. . . Yes, I am an activist. I volunteer for Obama and have spent many days canvassing, phoning, and working in several Obama offices.

As in forms of fandom across the spectrum of popular culture, support for political causes is thus grounded in the multilayered engagement with multiple and interconnected fields of textuality composed of urtexts and paratexts out of which readers construct and subsequently negotiate fan objects. Hence, analysing the processes of reading in which fans' habitus serves as the key agent of textual selection and negotiation is an important first step in developing an understanding of the affective attachments, and by extension the trust that is formed between media audiences and mediated objects.

\section{Attachment and trust}

Whereas the first and second waves of fans studies were primarily concerned with questions of community, power and resistance or lack thereof in fandom (cf. Gray et al., 2007), the field's third wave has focused on conceptualizing the affective bond between fans and their fan object. Much of this work has thus drawn on psychoanalytical theory and, naturally, given its focus to the interplay between self and external, mediated object and object-relations theory in particular. Stacey (1994) and Elliott (1999) draw on Melanie Klein's analysis of processes of projection and introjection through which the self seeks to balance the self and its drives. In this approach external (fan) objects thus serve as spaces signifying good elements of self that are projected onto the object; to maintain such projections, the meaning that fans create in their reading of fan objects must closely match the fan's expectations reflecting the projected aspect of self.

In a less conflict-centred account of human development, DW Winnicott (2000 [1967]) examines transitional spaces and objects between self and the object world, such as teddy bears or blankets, which in early childhood function as a first 'not-me' object that are found and created by the child and thus, despite their status as an external object, obtain emotional relevance through a form of attachment by expressing a sense of ownership through which the object functions as a controllable object and hence space of security as well as space of reality testing and play. Harrington and Bielby (1995) have usefully applied the notion of transitional spaces to their analysis of soap opera fans, as has Matt Hills (2002) to a range of further fan cultures. Here fan objects function as space between the self and world, that link the self to its environment, allowing the toleration of the separation between self and primary caregiver and hence foster a sense of security and belonging.

Finally, in my own work (Sandvoss, 2003, 2005a) I have suggested that the bond between fan and fan object moves beyond one of mere sense of possession; rather the fan object, in an act of narcissistic self-reflection, serves as an extension of self. The affective attachment to the fan object consequently derives from our inherent fascination with the extension of self into the object world (cf. McLuhan, 1964). In this sense, the often highly 
personal accounts of objects of fandom come to reflect the reader's Weltanschauung and self-identity. Such narcissistic-affective engagements are therefore not an entropic state of self-love but a form of engagement with the object world through the prism of self.

All three of these approaches are instructive in analysing the affective dimensions of political participation. Elliott (1996) suggests that the binary mode of perception that follows from the projection and introjection of perceived 'good' and 'bad' elements of self is at the heart of dichotomous political discourse that has, for example, increasingly shaped the US American political landscape. Similarly, the often strong biographical roots of political support and the profound sense of belonging that many political activists derive from this support indicate qualities of a bond between political fan and fan object akin to the function of transitional objects. Indeed, the strong emphasis of many political campaigns on themes of Heimat, home and belonging, further highlights the importance of the construction of connections between the self and the world, and the promise of a meaningful, secure place of the self in the world that is partly achieved vis-a-vis the transitional object. Finally, many interviewees revealed a close reading of their fan object in which its meaning seemed to intrinsically intersect with fans' sense of self. Obama (2006), who himself acknowledged that he expects to serve as the space for the reflection of widely varying values and aspirations he cannot possibly meet, presented such a space for the reflections of supporters' most passionate believes during the 2008 election campaign. As Liz, a 41-year-old supporter from Florida, recounts:

He makes me want to be a better person. He gives me hope that we can fix this country's problems and that my daughter can have a future. If anyone can be a beacon for positive change, it's him. He's not black or white, but both. He's an everyman. (Liz, 41, from Florida)

Hence, Obama supporters' engagement in political debates takes on a profound personal and emotional dimension:

I supported Kerry in 2004, and my governor in the gubernatorial election of 2006, and I educated myself on their campaigns and views. But it pales in comparison to the interest I feel in this campaign. I have put so much of my energy and interest into this campaign, that it has become something very personal. Attacks on Obama feel like attacks on me personally. Saying that Obama's ideas are wrong, feels like I'm being told my ideas are wrong as well. Largely, I think this is because I do feel so in line with his ideas. I agree with his views on almost every subject. (Laura, 27, from Michigan)

As much as fans find themselves in, say, the lyrics of Bruce Springsteen, because they create meaning in the process of reception (Cavicchi, 1998; Sandvoss, 2005a), Laura's reading of Barack Obama's candidacy is based on a reflective reading informed by her sense of self. The distinctively polysemic nature of political communication that allows for such self-reflective readings in turn arises out of the complexity of textual fields in convergence culture described above, therefore constituting the premise of the fan-like support of political causes that was so widely noted in the form of the grassroots and social media campaign fuelling Obama's 2008 campaign.

While a detailed critique of these approaches to the bond between fan and fan object is beyond the scope of this article, three important observations and conclusion follow: first, the key concept spanning across these three approaches is that of attachment. Second, this affective attachment of supporters is based upon an actual or perceived proximity between themselves and the fan text that is commonly achieved through the radical appropriability and hence advanced polysemy of mediated texts. Third, combining the two themes of trust and fandom, exploring how attachment among political supporters is formed is central to understanding how trust, as the fundamental form of relationship in the working of mass democracies as much as modern societies at large, is built and lost in political communication.

\section{From trust to disappointment}

Suggesting that trust is a 'way of managing, that is reducing distance' (Silverstone, 2007: 125), I think, has confused cause and consequence. Trust is an expression of reduced distance, rather than a mechanism of reducing distance. In this sense, media's lack of ability to maintain forms of affective attachments between politicians and their supporters is possibly less the cause of a lack of trust as Silverstone suggests, but rather its symptom.

The enthusiasm that supporters and activists bring to given political causes is in turn rooted in affective attachments based on fan texts meeting fans' sets of expectations through which the above described emotional bonds between fan and fan object are maintained. Fandom necessitates the horizon of expectation of fans to be met. This horizon, as I have suggested elsewhere (Sandvoss, 2005b, 2007a, 2011b), remains usually unchallenged for the highly polysemic nature of fan texts that in their far reaching absence of intersubjective meaning can become de facto neutrosemic, i.e. devoid of commonly shared meaning. Political marketing has long aimed at precisely such neutrosemy: creating texts that accommodate the widest possible number of reflective and consequently conflicting reading to achieve majority appeal (cf. Scammell, 1999). Political marketing has thus increasingly aimed to define political opponents' messages through so-called 'negative advertising'.4 
Yet, as I illustrated above, negative campaigns are among the many texts and paratexts between which fans select - and are thus are easily bypassed by fans' constructing the textual boundaries of their fan object. The greater challenge to political fans' trust is that the expectations, in which their affective attachments are rooted, fail to be met. As most fan objects, political parties and politicians evolve over time. The more polysemic any given cause appears, the greater the likelihood that individual fans' expectations are not met and trust gives way to disillusionment. The comparison between the supporters of Obama and the British Liberal Democrats is instructive here. Following Obama's victory in 2008, the Democrats lost their majority in the House of Representatives in the 2010 mid-term elections. Follow-up interviews with the initial participants of my 2008 study at the time of the mid-term elections in 2010 saw greatly reduced willingness to talk about their support, often indicating a degree of frustration. Some had ceased to support Obama altogether:

Obama has disappointed me more than I'd imagined he would. . . . His continual insistence on appeasing Republicans in

Congress (and out) is dismaying. He fails to act in a leadership capacity, instead deflecting major policy issues to

Congress. . . . Squandering an opportunity is sometimes worse than an outright loss. (Jill, 49, from Seattle)

A second group of Obama supporters also indicated that some of their expectations hadn't been met. However, their reading of Obama as fan object had not changed as they attributed the challenges to their initial expectations to external factors such as public opinion. As Laura observes:

I'm still a very strong supporter ... I feel satisfied with the progress made in health care reform and bringing an end to the war in Iraq. There's obviously still room to improve upon both, but in only two years, I feel important steps have been taken. I don't feel sufficient progress has been made to reduce our nation's dependence on oil and other limited natural resources. However, with the state of the economy, I'm not surprised the issue hasn't been the focus of policy making. I feel it's exceptionally important, but I understand that the majority of Americans would disapprove of their representatives focusing on renewable energy.

In the case of the LibDems, the decline in support has been more substantive. Entering into a coalition government with the Conservatives following the 2010 general election, many supporters saw themselves confronted with dramatically different policy decisions and hence a very different 'meaning' of the party than the one they had constructed prior to the election. Stuart, a 30-year-old television editor from Yorkshire, is representative of many interviewees:

My support has all but vanished since the election. Within days I was horrified to realize that I had empowered a Conservative government. The main players within the LibDems had completely sold out. To see Nick Clegg laughing and joking with David Cameron at the press conferences was enough to show that this wasn't just a case of them standing together for the sake of the country, etc., but was more than that. It all seemed to fit together too easily. Lastly Vince Cable's transition from left to right now seems complete with his willingness to sell off any remaining public owned assets, so I can say that I am totally dissatisfied with their role in government.

Similarly, Richard, a 20-year-old student from Cheshire, concludes:

Their main policy goal that interested me was their stance of being against rising tuition fees. But they didn't live up to their word, so I see no reason to believe anything they promise in the future. Such disillusionment is also reflected in nationwide surveys, with the LibDems being projected to have lost $60 \%$ of their support in the 15 months following the general election in 2010. The disappearance of trust in these cases cannot be reduced to mere questions of media coverage and reporting, as supporters remain selective in including and excluding textual episodes within the textual field from which their fan object is constructed. Instead, trust is eroded because of the incompatibility of a largely neutrosemic textual field at the time during which support is first built and subsequent actions by the fan object that fail to meet some or many supporters' expectations.

\section{Trust in the media? Trust in audiences!}

In coming to a final assessment of how political fandom impacts on trust in mediated, indirect democracies, a number of important qualifications need to be made. First, longitude of political support is an important factor in fans' capacity to maintain affective attachments even when key expectations are not met. Notably, Jill had originally supported Hillary Clinton during the primary campaign. Similarly, Stuart, had been a life-long Labour voter until his decision to support the Liberal Democrats in 2010. In contrast, participants with a longer history of supporting the LibDems expressed similar dissatisfaction with key policies, but were more willing to attribute these to particular circumstances (unfavourable election result) or particular actors (such as LibDem leader Nick Clegg) who could be separated from the actual fan object (the party).

Second, typologies of different fan groups are important in understanding key differences in the management of trust in political processes. Contrary to the common perception of fans as hapless followers, the bond between fan and fan object is inherently unstable and varies among different audience groups. The group that emerged to have lost least trust in the cause they initially supported closely matched Abercrombie and Longhurst's (1998) description of 'enthusiasts', those closely connected with others, who are highly productive and, crucially, whose object of fandom moves from the mediated object to their own activity. Participants in my study who still supported the Liberal Democrats fell exclusively into this category. Often having studied politics or related subjects, working for charities, think tanks or universities, their affective attachments to the nominal fan object were cautious from the beginning. In the same way that enthusiasts of sports teams or television programmes are 
more likely to critically reflect on the producers and owners they interact with closely (cf. Sandvoss, 2003, 2005a), political enthusiasts appear to regard their fan objects more as strategic allies than build attachments to the same extent as other fan groups. This habitus of qualified support is illustrated in George's account, who having worked in the City for over a decade, is highly critical of dominant financial market and asset management practices. George first became a supporter of Vince Cable, currently Business Secretary in the coalition government. According to George his 'ideas make a lot of sense . . . so the LibDems seemed the only hope'. George believes that Cable, although largely unnoticed by the public, has made important moves towards regulating financial industries. At the same time, George remains highly critical of other decisions of the party such as its initial support of a Conservative National Health Service Reform Bill which 'makes him shudder'. This is the topic on which George's political activism focuses most, having written three letters to his MP, LibDem Deputy Leader Simon Hughes:

I have picketed [Hughes's] office at the same time as picking up leaflets to hand on out on [the] referendum campaign from the same office! So I don't know what he thinks of me: 'who is that nutcase who campaigns on my behalf on one

topic and then comes in and beats me over the head and shouts with a megaphone at me on another topic on the same

day?' But I don't see there is inconsistency with that. They are different issues. (George, 39)

This form of selective support that many enthusiasts display is one strategy to address the key challenge political supporters are confronted with.

Thus, fourth, while near neutrosemic conditions of mediated textuality enable fans to read texts in ways that build a close affective bond, the very same neutrosemic condition facilitates conflicting reading positions and horizons of expectations that cannot be sustained over time. The more polysemic the fan text of a given political cause, the greater its potential for disillusionment. The campaigns of Obama and the Liberal Democrats centred on broad concepts of 'hope' or 'change', although among supporters of Obama I interviewed, four clear policy aspirations were shared almost universally (peace, establishing universal health care, new economic policies and investment in alternative energy). The expectations - and by extension the trust - of many Obama supporters have been challenged in that they regard progress on such policy goals as less complete than they wished. The challenge to expectations of LibDem supporters appears to have been yet more profound in that they perceive the party to have supported policies opposing its original aims.

A partial loss of trust in political movements whose support is grounded in the neutrosemic textuality of convergence media hence appears inevitable. A dramatic loss of trust such as that experienced by the LibDems may be attributed to failures of political leadership. However, in both cases trust is not solely impacted upon by processes of communication and individual agency but is also dependent on the democratic structures and systems of representation. Electoral systems that give sole representation to majority votes, such as the British first-past-the-post electoral system or the American electoral college, inevitably heighten the need for political actors to fuel the polysemy, and thereby vagueness, of their initial campaigns, leading to a subsequent loss of trust. In contrast, it is only more representative electoral systems that allow less polysemic political movements to prosper. Coinciding with the rise (and fall) of support for Obama in the USA and the Liberal Democrats in Great Britain, the German Green Party has made unprecedented electoral advances, unseating the centre-right CDU in state elections for the first time in the history of Germany's third largest state, Baden-Württemberg, in March 2011. As a Forsa poll from May 2011 suggests, the Greens subsequently increased their support from $24.2 \%$ (enough to head a coalition government with the social-democrats who took a $23.1 \%$ share of the vote), to around $30 \%$. The fact that support for the Greens grew indicates that their campaign, as much as the party's wider image, has a stronger denotative core focused on a range of environmental and social policies in which the affective attachments of its supporters are grounded in more intersubjective readings that remain unchallenged by the party's actions after taking power. At the same time, the Greens electoral 'victory' on this clearer and therefore narrower platform was achieved with only a slightly higher share of votes than the LibDems achieved in 2010, when winning a mere 62 out of 650 seats in the Houses of Commons. Electoral systems thus prejudice the extent to which political parties and politicians can match the expectations and their associated emotional investments, not least in the form of trust, of their supporters.

For those seeking to halt and reverse the erosion of trust in political communication and the democratic process alike, two conclusions follow. Convergence media foster the rise of affective attachments and engagement in political causes. Yet regardless of the potential of digital media to widen the participation in political discourses, the structures of democratic representation are fundamental in maintaining trust in political systems and their actors. In this sense this study lends support to those who, like Garnham (1992), have remained sceptical about the seemingly more participatory public sphere of the broadcast and now convergence media age, because the link between political discourse and governmental and legislative processes remains limited. On the other hand, the affective attachments of political fans of which trust is a key articulation, do not, as Habermas (1989) might have suggested, impact negatively on the political process. Rather, as much as fandom in other realms, they function as a catalyst in which existing political, social and economic conditions are invested in with greater intensity, yet subsequently found to be lacking (cf. Sandvoss, 2005a). While such disillusionment may give rise to apathy, it is nevertheless a process of learning and realization. Becoming a (political) fan with its associated need to select from the plethora of associated media content across different 
platforms, thus - and here I return to Silverstone's (2007) wider concern in his analysis of trust - is a means of building media literacy. The maintenance of trust, then, is no aim in and for itself. In fact its absence constitutes an important step in media audiences as citizens challenging existing, yet lacking forms of political representation.

\section{Funding}

This research received no specific grant from any funding agency in the public, commercial, or not-for-profit sectors.

\section{Notes}

1. As Giddens (1990) notes, trust and hope are closely related concepts in which trust merely expresses a greater degree of certainty.

2. Both Ruddock (2005) and myself (Sandvoss, 2007b) have illustrated how, for example, football fandom and in particular fans' enunciative productivity online in the form of contributions to fan fora and discussion groups are part of the contemporary, mediated public sphere, or what Hartley (1997) describes as semiosphere. Others, such as John Street (1997), have highlighted the interplay between popular music and politics.

3. Mirroring the emphasis of fan studies' third wave, the focus here is on how an affective bond is created between a given audience member and their (political) fan object - the particular textual formation that becomes the focal point of support, identification and enthusiasm in what John B Thompson (1995) described as forms of mediated quasiinteraction between media audiences and public figures based on non-reciprocal intimacy at a distance.

4. During the 2005 UK general elections, for example, campaign posters by the two major parties, Labour and Conservatives, thus rarely featured their own leaders but instead sought to delineate - and hence make less polysemic the messages of the political opponent, with Conservative leader Michael Howard commonly featured on Labour posters and Prime Minister Tony Blair a regular stay on Conservative campaign material.

\section{References}

Abercrombie N and Longhurst B (1998) Audiences: A Sociological Theory of Performance and Imagination. London: Sage.

Cavicchi D (1998) Tramps Like Us: Music and Meaning among Springsteen Fans. New York and Oxford: Oxford University Press.

Coleman S (2003) A tale of two houses: The House of Commons, the Big Brother House and the people at home. Parliamentary Affairs 56: 733-758.

Elliott A (1996) Subject to Ourselves: Social Theory, Psychoanalysis and Postmodernity. Cambridge: Polity.

Elliott A (1999) The Mourning of John Lennon. Berkeley: University of California Press.

Fiske J (1992) The cultural economy of fandom. In: Lewis LA (ed.) The Adoring Audience. London: Routledge.

Garnham N (1992) The media and the public sphere. In: Calhoun C (ed.) Habermas and the Public Sphere, 6th edn. Cambridge, MA: MIT Press.

Giddens A (1990) The Consequences of Modernity. Cambridge: Polity.

Gray JA, Sandvoss C and Harrington CL (2007) Introduction: Why study fandom? In: Gray JA, Sandvoss C and Harrington CL (eds) Fandom: Identities and Communities in a Mediated World. New York: New York University Press.

Habermas J (1989) The Structural Transformation of the Public Sphere. Cambridge, MA: MIT Press.

Harrington CL and Bielby D (1995) Soap Fans: Pursuing Pleasure and Making Meaning in Everyday Life. Philadelphia, PA: Temple University Press.

Hartley J (1997) The sexualization of suburbia: The diffusion of knowledge in the postmodern public sphere. In: Silverstone R (ed.) Visions of Suburbia. London: Routledge.

Hills M (2002) Fan Cultures. London: Routledge.

Jauss HR (1982) Toward an Aesthetic of Reception. Minneapolis: University of Minnesota Press.

Jenkins H (1992) Textual Poachers: Television Fans and Participatory Culture. New York: Routledge.

McLuhan M (1964) Understanding Media: The Extension of Man. London: Routledge.

Obama B (2006) The Audacity of Hope. New York: Random House.

Ruddock A (2005) Let's kick racism out of football - and the lefties too! Journal of Sport and Social Issues 29(4): 369-385.

Sandvoss C (2003) A Game of Two Halves: Football, Television and Globalization. London: Comedia.

Sandvoss C (2005a) Fans: The Mirror of Consumption. Cambridge: Polity.

Sandvoss C (2005b) One dimensional fan: Toward an aesthetic of fan texts. American Behavioural Scientist 49(3): 822-839.

Sandvoss C (2007a) The death of the reader? Literary theory and the study of texts in popular culture. In: Gray JA et al. (eds) Fandom: Identities and Communities in a Mediated World. New York: New York University Press.

Sandvoss C (2007b) Public and publicness: Media sport in the public sphere. In: Butsch R (ed.) Media and Public Spheres. Basingstoke: Palgrave.

at University of Surrey on July 25, 2013 ejc.sagepub.com Downloaded from SandvOSS 81 
Sandvoss C (2011a) Fans online: Affective media consumption and production in the age of convergence. In: Christensen M, Jansson A and Christensen C (eds) Online Territories. New York: Peter Lang.

Sandvoss C (2011b) Reception. In: Nightingale V (ed.) Handbook of Media Audiences. Malden, MA and Oxford: Blackwell. Scammel M (1999) On Message: Communicating the Campaign. London: Sage.

Silverstone R (2007) Media and Morality. Cambridge: Polity.

Stacey J (1994) Stargazing: Hollywood Cinema and Female Spectatorship. London: Routledge.

Street J (1997) Politics and Popular Culture. Philadelphia, PA: Temple University Press.

Thompson JB (1995) The Media and Modernity. Cambridge: Polity.

Winnicott DW (2000 [1967]) Transitional objects and transitional phenomenon. In: Du Gay P, Evans J and Redman P (eds) Identity: A Reader. London: Sage.

Van Zoonen L (2005) Entertaining the Citizen. Lanham, MD: Rowman and Littlefield. 